\title{
Functional Anorexia in School-age Children
}

\author{
Differentiation of Anorexia Nervosa from Other Psychiatric \\ Causes of Refusal to Eat
}

\author{
ELVA POZNANSKI, M.D.*
}

\begin{abstract}
A NOREXIA nervosa, in which starvation is motivated by psychologic factors, has been recognized as a clinical entity since Gull's classic description in 1868. His description included loss of appetite, slow pulse, amenorrhea, constipation, slow respiration and emaciation. He commented also on the restlessness and its occurrence in young girls. Most authors accept anorexia without organic cause as the primary feature of anorexia nervosa, with amenorrhea and hyperactivity as findings frequently associated. ${ }^{1,3,5}$ Anorexia nervosa is typically severe, has a long chronic course and can be life-threatening.

Pediatricians should be able to differentiate anorexia nervosa from anorexia related to other psychiatric disorders. This differentiation can be most helpful in management, particularly when the guidance of a child psychiatrist is not available.

We present here the case history of an early adolescent girl with anorexia nervosa, to be contrasted with summaries of two preadolescent girls whose chief symptom was refusal to eat without organic basis. All three cases had been referred for psychiatric consultation as possible cases of early anorexia nervosa, based on their refusal to eat.
\end{abstract}

\section{Anorexia Nervosa}

Nancy was a 12-year-old girl, the eldest of six children in a strict Roman Catholic family. Four months prior to psychiatric referral, although already quite slender, Nancy dieted for five to six weeks, dropping her weight from 90 to 78 pounds. The following incident prompted the dieting. Nancy had read a newspaper story about a rape incident and had become exceedingly curious about what had actually happened and had ques-

* Instructor in Department of Psychiatry, University of Michigan Medical School, Ann Arbor, Mich. 48104 . tioned her mother in great detail. Subsequently she became fearful that she could somehow become pregnant, although she had never had even social contacts with boys. Her menarche had occurred when she was 11 years old, but she missed her last four or five periods before coming to the psychiatrist. For the past few months, Nancy had continued to refuse food and had upset her family by both hiding food and throwing it away when the parents were not looking.

Nancy was extremely emaciated, tomboyish in appearance and looked considerably younger than her age. She had no desire to grow up and felt that being a teenager would be unpleasant. She readily expressed a fear of being "mentally ill." Most of Nancy's interests were distinctly masculine. She had no close friends and at home she was frequently angry and irritable with her younger siblings. Nancy increased her physical activity in every conceivable way, including vigorous exercises. This information was obtained from Nancy, as her parents remained unaware of her increased activity for a long time. Schoolwork was the only sphere in which Nancy functioned without difficulty, achieving mostly A's.

Nancy had all of the cardinal features of anorexia nervosa, namely, severe weight loss, amenorrhea and hyperactivity. In addition, she demonstrated an unusual type of behavior in hiding food and throwing it away, as well as a great deal of confusion about pregnancy and sexuality. This clinical picture is characteristic of true anorexia nervosa.

For six months Nancy was seen twice a week in outpatient psychiatric therapy. Her relationship with the therapist was moderately positive and she would tend to gain weight just before visits and then lose it during the intervals between visits. Nancy' ideas about food and eating were bizarre. She thought that even a very small amount of food would cause her stomach to ache and that it would become unbearably distended. Her tendency to withdraw became more and more evident and she would isolate herself in her room whenever any visitors would come. During therapy Nancy was exceedingly curious about her body and had a great many questions, but simultaneously displayed a certain detachment as if her body was 
not real and did not belong to her. Masochistic trends, where she deliberately enjoyed pain, were noted. For example, she refused to wear mittens in the winter and would not use any hand lotion even when her hands were red and chapped. The possibility of latent psychosis was suggested by a lack of affect and bizarre fantasy material.

During a six-month period of outpatient therapy, Nancy's weight dropped five pounds and she began to have dizzy spells. Hospitalization for tube feeding was arranged by her pediatrician. When she was hospitalized and confronted with tube feeding she immediately began to eat three meals. After a one-week stay her behavior also noticeably improved. She became more spontaneous in talking, was less difficult at home and was less withdrawn. During the next few months a great deal of time was spent in frank discussions about sex, as these kinds of discussions were taboo within her own family. Her relationhip at home continued to improve and she became somewhat more accepting of her temininity.

\section{Pseudoanorexia Nervosa}

Michelle, a bright thin tense nine-year-old girl, was referred for psychiatric consultation because of her refusal to eat solids for the past seven to eight weeks. Her diet had consisted chiefly of milk; hence, her pediatrician had given her additional vitamins and mineral supplements. She suffered a mild weight loss (about five pounds) which was particularly noticeable because of her preceding slimness.

The mother was an attractive but extremely anxious and somewhat phobic woman. She described Michelle as a "picky" eater who had disliked trying new foods since infancy. Whether enough food was consumed each mealtime had been provoking hovering concern and obvious anxiety in her parents for many years. The onset of refusing to eat solids was precipitated by an episode two months earlier, at which time the paternal grandmother was a houseguest. This grandmother was a markedly fearful, hysterical woman who continually reminded Michelle to chew each bite 28 to 30 times during mealtime. One evening Michelle's brother choked while chewing some food. Immediately the grandmother became excited and screamed that the boy was dying; it took more time to calm the grandmother than to stop the boy's choking. Immediately after this incident, Michelle stopped eating solids. Her refusal to eat was based on a fear of choking on solids.

Michelle talked easily about her fear of swallowing and readily related it to the above incident. She spoke with relief of her fear of her brother choking, as well as additional fears of bugs and of the dark. Michelle was doing well academically in school and was able to form several friendships with children her own age. Within the family it was apparent that Michelle was openly fond of her father and was competitive with her mother. While this behavior was not abnormal, it was perhaps a bit exaggerated for her age. The infuence that the family played on her eating was highlighted by Michelle's far greater food consumption when she ate away from home.

Michelle's attitude towards food itself was normal, nor did she have any other bizarre or unusual ideas.

During the time that Michelle was seen in therapy, her eating gradually improved. Disentangling the parental anxieties and concerns from Michelle's difficulties proved one of the major hurdles in therapy. At termination Michelle's eating was sufficient nutritionally, although she remained a somewhat picky eater.

Valerie was an eight-year-old girl, whose mother contacted her pediatrician because of the child's recent behavioral change and excessive concerns about death and dying. Recently, Valerie also had refused to eat.

A month prior to the referral, the family one evening discussed the death of a television performer, as well as the death of a close relative. Valerie listened intently, but offered no comment. Within two days of this discussion the mother noticed that Valerie appeared tense and worried, her appetite had decreased and she continually expressed fears of death and dying. During the ensuing weeks, Valerie developed complaints of breathlessness, vague chest pains, epigastric pains and the feeling her heart might have stopped beating. She lost about three pounds in three weeks. She told her pediatrician she disliked food.

Valerie was a sensitive, overconscientious little girl, who did well in school and was overly concerned with being good. She expressed many somatic fears which had existed long before the previous month. In reference to eating, she said that she was afraid to swallow because of the fear that she might choke and die. She freely discussed the relative's death and could relate it to the onset of her own fear of swallowing, as well as her fears of death. Valerie's distress over the death of the relative was much augmented by her own personality characteristics. With an opportunity to verbalize her anxiety Valerie went back quickly to her previous level of functioning.

\section{Discussion}

That all three cases were girls fits in with the extreme rarity of anorexia nervosa in boys. While anorexia nervosa appears more frequently in adolescence there have been well-documented cases in preadolescent girls with the same chronic course. ${ }^{5}$ The young age of our last two patients does not exclude the possibility of anorexia nervosa; however, it does weigh against this diagnosis.

Anorexia nervosa varies considerably in severity. The textbook picture of a living skeleton is rarely seen in outpatient prac- 
tice. On initial evaluation the degree of severity is helpful but of limited diagnostic value.

Anorexia nervosa tends to begin insidiously and goes unrecognized for a long time by the parents. Nancy's parents exemplified this attitude, whereas the parents of the last two girls reacted immediately to the behavioral changes.

The precipitating event in Nancy's illness was a relatively common incident, i.e., a newspaper story, but was sought out to serve as a vehicle to express her own inner turmoil. In the other two girls their psychiatric disturbance had a relatively acute onset, and in both cases there were realistic events surrounded by an atmosphere of anxiety in the family which served as precipitating factors. Though both reality and fantasy factors were operating in all three girls, the proportions were vastly different. There was considerably more fantasy element in the first case and more evidence of realistic, environmental factors in the last two cases.

All three girls had weight loss and refusal to eat. Hence this symptom alone cannot be used to distinguish anorexia nervosa from other psychiatric anorexia. Differentiation must be made by assessing other factors.

The psychologic factors underlying Nancy's refusal to eat related to fantasies of becoming pregnant, including unusual ideas about her body. Beside the disturbance in Nancy's thoughts, her conflicts extended into the interpersonal area with severe difficulties relating to people. Problems in sexual identification were manifest by her masculine behavior and denial of any interest in femininity.

Psychic disturbances are a cardinal feature of anorexia nervosa. The nature of the disturbance can range from neurosis to psychosis (a certain proportion seem to be schizophrenic) without there being a specific diagnostic entity. ${ }^{1,5}$

The three essential psychiatric features of anorexic nervosa are:

1. Grossly disturbed ideas about the body. A common concern is that a slight protuberance of the abdomen means "pregnancy" or "fat."

2. Disturbed interpersonal relationships in almost every sphere, e.g., with family or friends of the same age.
3. Problems with activity and passivity, frequently manifest as excessive exercises and general hyperactivity.

The last two girls had a fear of swallowing without unusual concerns about food or their appearance. In Michelle, the fear of swallowing could be linked to the fear of her brother choking. The unconscious wish for her brother to choke provoked a great deal of anxiety which Michelle handled by expressing the fear that she herself might choke. The attitudes of the adults lent reality to the fear that choking would cause death. With Valerie the fear of swallowing also was linked with death, although the specific psychodynamics are less clear. The fear of swallowing alone provoked the refusal to eat.

The last two girls were mildly neurotic. Obsessive-compulsive trends and hypochondriacal complaints were evident. In addition to the fear of swallowing, the immediate concern, their fears extended to several other areas but without severe personality distortions. They were able to perform well academically; they had friends in their own peer groups and were able to relate to their parents, despite some noticeable areas of conflict.

In these last two girls the course of the illness was distinctly different from that of anorexia nervosa. The symptoms of fear of swallowing and weight loss were quickly controlled with a ready reversal of refusal to eat. The second case required longer psychotherapy than the third due to personality factors and family pathology. In contrast, the girl with true anorexia nervosa showed the typical prolonged, chronic course of this disease, with great resistance to eating for a long period of time.

\section{References}

1. Bliss, E., Bliss, B. and Hardin, C. H.: Anorexia Nervosa. New York, Hoeber, Inc., Harper \& Brothers, 1960.

2. Bruch, H.: The insignificant difference; discordant incidence of anorexia nervosa in monozygotic twins. Amer. J. Psychiat. 126: 85, 1969.

3. Horigan, F. D.: Anovexia nervosa; a literature survey. Psychol. Abstracts, No. 2, National Institute of Mental Health.

4. Rollins, N, and Blockwell, A.: The treatment of anorexia nervosa in children and adolescents; stage I. J. Child Psychol. Psychiat. 9: 81, 1968.

5. Thoma, H.: Anorexia Nervosa. New York, International Universities Press, Inc, 1967.

6. Warren, W.: A study of anorexia nervosa in young girls. J. Child Psychol. Psychiat. 9: 27, 1968. 